\title{
Editorial
}

Nephrology

\section{Placental Growth Factor as a Novel Marker in Uremia-Related Cardiovascular Disease}

\author{
Christina W. Chen S. Ananth Karumanchi \\ Division of Nephrology, Beth Israel Deaconess Medical Center and Harvard Medical School, \\ Boston, Mass., USA
}

It has been well established that chronic kidney disease is an independent risk factor for adverse cardiovascular events [1]. The exact etiology of this phenomenon is not known, but the risk is thought to be multifactorial and due to uremia-specific processes that may not respond to traditional cardiovascular preventive strategies.

Extensive research has been done to understand the underlying pathophysiology in order to better categorize patients based on risk and to explore preventive therapies. In particular, several novel biomarkers such as carbamylated albumin have been proposed as pathogenic markers mediating excess mortality related to end-stage renal disease (ESRD) [2]. Placental growth factor (PIGF) is a circulating protein that belongs to the family of vascular endothelial growth factors (VEGFs); it is emerging as another promising biomarker. The article by Matsui et al. [3] published in this issue of AJN evaluates the prognostic value of PlGF in predicting mortality and cardiovascular events in ESRD patients on dialysis. They conducted an observational study involving 205 dialysis patients who received a cardiac catheterization; 162 (79\% of patients) were on hemodialysis and 43 (21\% of patients) were on peritoneal dialysis. Both PlGF and VEGF levels were obtained and echocardiography was obtained within 2 weeks of blood sampling. The patients were followed for at least a year with a median follow-up period of 20 months. The primary endpoint was death from any cause or a cardiovascular event including non-fatal newly developed CAD, stroke, peripheral arterial disease, aortic disease, and heart failure. During the follow-up period, there were 121 patients who reached a primary endpoint. An above-median PlGF level was associated with a hazard ratio (HR) of 2.55 (1.72-3.83), which was higher than the HR for having an above-median VEGF, 1.39 (0.95-2.04). A multimarker predictive model involving 5 markers, including PlGF, found that 2,3 , and 4 positive markers had a 3.82-, 5.77-, and 6.59-fold higher risk of a primary endpoint. This article concludes that PlGF is both independently and significantly associated with mortality and cardiovascular events and a useful prognostic marker. The strengths of this study include a median follow-up period of 20 months, complete retention of patients with no loss to follow-up, and a high percentage of patients reaching a primary endpoint.

During the last decade, PlGF biology has inspired research spanning from pregnancy to cancer to cardiovascular disorders. While VEGF is required for normal development of healthy vasculature, PIGF has a redundant role in health. In fact, mice deficient in PlGF do not display phenotypic abnormalities [4]. PlGF does however have a

\section{KARGER 125}

(c) 2015 S. Karger AG, Base

$0250-8095 / 15 / 0422-0115 \$ 39.50 / 0$
S. Ananth Karumanchi, MD

Beth Israel Deaconess Medical Center

330 Brookline Avenue, RN-370D

Boston, MA 02215 (USA)

E-Mail sananth@bidmc.harvard.edu 
non-redundant role in disease states such as tissue ischemia, malignancy, and inflammation. It has been shown to be a pleiotropic factor in blood vessel growth and maturation and it enhances the proliferation, migration, and survival of endothelial cells. Neutralization of PlGF has been shown to inhibit vessel growth in injured, ischemic, or inflamed tissues. PlGF has been shown to be strongly up-regulated in early and advanced atherosclerotic disease and is even thought to be a primary cause of unstable plaque formation [5]. Multiple studies have evaluated the use of circulating PlGF levels as a predictive biomarker for assessing cardiovascular risk. PlGF selectively binds to its receptor, Flt-1, and accelerates the atherosclerotic process through increased intramural angiogenesis and monocyte recruitment [6]. In clinical studies, PlGF was identified as being a predictive marker for both short- and long-term cardiovascular events [7, 8]. Rambod et al. [9] found that PlGF was elevated in patients in a study of 310 CKD patients and that a higher level of PlGF was associated with increased mortality but not with cardiovascular events. However, a recent larger cohort study of 1,351 CKD patients by Matsui et al. [10] found that higher PlGF levels were associated with an increase in mortality over a 3 -year follow-up period with cardiovascular risk in the highest quartile having an HR of 8.42 (5.54-13.3).

Cardiovascular mortality is markedly elevated in dialysis patients, who are known to be in a chronic inflammatory state. Additional investigation is needed to determine whether elevated PlGF contributes to this inflammatory state or is secondary to the inflammation. Larger studies will need to be conducted to determine if the results reported by Matsui et al. [10] can be replicated clinically and whether measurement of additional molecules in this pathway, such as sFlt-1, adds additional predictive value [11]. As PlGF is involved mostly with disease processes and appears redundant in healthy vasculature, it may also be a therapeutic target and we should look forward to additional studies addressing these questions.

\section{Disclosure Statement}

The authors have no conflict of interest to declare.

\section{References}

1 Gansevoort RT, Correa-Rotter R, Hemmelgarn BR, Jafar TH, Heerspink HJ, Mann JF, Matsushita K, Wen CP: Chronic kidney disease and cardiovascular risk: epidemiology, mechanisms, and prevention. Lancet 2013; 382:339-352.

$>2$ Berg AH, Drechsler C, Wenger J, Buccafusca R, Hod T, Kalim S, Ramma W, Parikh SM, Steen H, Friedman DJ, Danziger J, Wanner C, Thadhani R, Karumanchi SA: Carbamylation of serum albumin as a risk factor for mortality in patients with kidney failure. Sci Transl Med 2013;5:175ra29.

3 Matsui M, Sanejima K, Takeda Y, Tanabe K, Morimoto K, Tagawa M, Onoue K, Okayama S, Kawata H, Kawakami R, Akai Y, Saito Y: Prognostic impact of placental growth factor on mortality and cardiovascular events in dialysis patients. Am J Nephrol 2015;42:117125.

$\checkmark 4$ Carmeliet P, Moons L, Luttun A, Vincenti V, Compernolle V, De Mol M, Wu Y, Bono F, Devy L, Beck H, Scholz D, Acker T, DiPalma T, Dewerchin M, Noel A, Stalmans I, Barra A, Blacher S, VandenDriessche T, Ponten A, Eriksson U, Plate KH, Foidart JM, Schaper W, Charnock-Jones DS, Hicklin DJ, Herbert JM, Collen D, Persico MG: Synergism between vascular endothelial growth factor and placental growth factor contributes to angiogenesis and plasma extravasation in pathological conditions. Nat Med 2001;7:575-583.

$>5$ Luttun A, Tjwa M, Moons L, Wu Y, AngelilloScherrer A, Liao F, Nagy JA, Hooper A, Priller J, De Klerck B, Compernolle V, Daci E, Bohlen P, Dewerchin M, Herbert JM, Fava R, Matthys P, Carmeliet G, Collen D, Dvorak HF, Hicklin DJ, Carmeliet P: Revascularization of ischemic tissues by PlGF treatment, and inhibition of tumor angiogenesis, arthritis and atherosclerosis by anti-Flt1. Nat Med 2002;8:831-840.

$\checkmark 6$ Khurana R, Moons L, Shafi S, Luttun A, Collen D, Martin JF, Carmeliet P, Zachary IC: Placental growth factor promotes atherosclerotic intimal thickening and macrophage accumulation. Circulation 2005;111:28282836.

7 Heeschen C, Dimmeler S, Fichtlscherer S, Hamm CW, Berger J, Simoons ML, Zeiher AM; CAPTURE Investigators: Prognostic value of placental growth factor in patients with acute chest pain. JAMA 2004;291:435-441.

$\checkmark 8$ Lenderink T, Heeschen C, Fichtlscherer S, Dimmeler S, Hamm CW, Zeiher AM, Simoons ML, Boersma E; CAPTURE Investigators: El- evated placental growth factor levels are associated with adverse outcomes at four-year follow-up in patients with acute coronary syndromes. J Am Coll Cardiol 2006;47:307-311.

$\checkmark 9$ Rambod M, Heine GH, Seiler S, Dominic EA, Rogacev KS, Dwivedi R, Ramezani A, Wing MR, Amdur RL, Fliser D, Raj DS: Association of vascular endothelial factors with cardiovascular outcome and mortality in chronic kidney disease patients: a 4-year cohort study. Atherosclerosis 2014;236:360365.

10 Matsui M, Uemura S, Takeda Y, Samejima KI, Matsumoto T, Hasegawa A, Tsushima $\mathrm{H}$, Hoshino E, Ueda T, Morimoto K, Okamoto K, Okada S, Onoue K, Okayama S, Kawata H, Kawakami R, Maruyama N, Akai Y, Iwano M, Shiiki H, Saito Y; NARA-CKD Investigators: Placental growth factor as a predictor of cardiovascular events in patients with CKD from the NARA-CKD study. J Am Soc Nephrol 2015;pii:ASN.2014080772.

11 Di Marco GS, Reuter S, Hillebrand U, Amler S, König M, Larger E, Oberleithner H, Brand E, Pavenstädt H, Brand M: The soluble VEGF receptor sFlt1 contributes to endothelial dysfunction in CKD. J Am Soc Nephrol 2009;20: 2235-2245. 